\title{
Experiences and Health-seeking Behaviour of Couples in Ekiti-State Nigeria towards Infertility
}

Deborah Tolulope Esan ( $\nabla$ esandt@abuad.edu.ng)

Afe Babalola University College of Medicine and Health Sciences https://orcid.org/0000-0002-3896-8207

Kelechi Queedaline Nnamani

Afe Babalola University College of Medicine and Health Sciences

Agatha Ogunkorode

Afe Babalola University College of Medicine and Health Sciences

Fatimah Muhammad

Afe Babalola University Multisystem Hospital, Ado-Ekiti

Olamide Oluyemisi Oluwagbemi

Ekiti State University teaching Hospital, Ado-Ekiti

Research article

Keywords: Infertility, Perception, Experiences of couples, Nigeria African Context.

Posted Date: August 19th, 2020

DOI: https://doi.org/10.21203/rs.3.rs-46818/v1

License: (c) (1) This work is licensed under a Creative Commons Attribution 4.0 International License. Read Full License 


\section{Abstract}

Background: Infertility has been described as the most important reproductive health concerns of Nigerian women. Based on the importance placed on offspring in the African context, infertility contributes to high level of psychological distress, conflicts between couples and subject those faced with the challenge to hazardous sexual behaviors. This study therefore explored the experiences and health-seeking behaviors of couples towards infertility.

Methods: The study employed a qualitative research design. In-depth interviews were conducted with fifteen participants who had been diagnosed with primary or secondary infertility, who were currently receiving treatment at a tertiary health institution in the Ekiti State. Thematic categorization and content analysis was used to analyze the data.

Results: Majority of the participant were Female (14 out of 15), between the ages of 20-35(80\%) and are Christian (100\%). All the participants reported negative emotional and psychological effects of infertility as they all expressed their unhappiness on the issue of infertility and claimed that the issue has affected them in all spheres of life (socially, marital relationship and psychologically). Two of the participants claimed that their husbands had abandon them because of their inability to conceive. Majority of the participants also claimed that there is social stigma associated with the condition as almost all (14 of 15) said the society is not doing anything to support women facing infertility issue. All the participants utilized medical treatments in combination with religious activities as a form of treatment.

Conclusion: The society is not doing enough to support couples with infertility issue. Supports group should be created in the society where couples with similar challenge can come together to freely discuss and share their experiences as this could help in alleviating the psychological distress associated with infertility.

\section{Background}

Infertility can be defined as a condition manifested through the inability to conceive and to achieve a successful clinical pregnancy after 12 months of regular and unprotected sexual intercourse, among women aged 1549 years [1]. Infertility is a reproductive health problem worldwide, it affects over $10 \%$ of the word population, affecting about 30\% in Sub-Saharan Africa [2, 3]. Infertility has been described as the most important reproductive health concerns of Nigerian women. Estimations from demographic health surveys data stated that the prevalence rate as $11 \%$ while clinical based studies suggested rates between $14.5 \%-30 \%[4,5,6]$. Infertility can be categorized as primary or secondary. Primary infertility happens when there is the inability to achieve conception and to have a successful live birth without ever having a child. On the other hand, secondary infertility is the inability to achieve conception and have a successful live birth when individuals have already had a previous biological child [7].

In Nigeria the prevalence of primary and secondary infertility is $5 \%$ and $8 \%$ respectively [7]. The causes of infertility vary widely, several environmental, occupational, genetic and infectious diseases have been identified as the causes of infertility, Both genders are affected in $40 \%$ of cases but the most common reasons for reproductive issues are related to gynecologic and other conditions, such as ovulatory disorders $(25 \%)$, fallopian tubal damage $(20 \%)$, and uterine or peritoneal abnormalities $(10 \%)$. Also, in $30 \%$ of cases of infertility, causes are unknown $[8,9$, 10]. 
Infertility is a condition that attracts stigma in the society, one of the major reason is due to the fact that childbearing is placed as the hallmark of womanhood, and an inability to bear the children makes the society see the woman as incomplete [4]. Infertility has been recognized as a potentially serious, costly and burdensome issue for affected families [8], the discovery that one cannot become pregnant due to biochemical and/or anatomical problems is often unforeseen and results in invasive and demanding medical tests for both men and women [9]. Furthermore, infertility may put a strain on the couple's relationship causing feelings of shame, anger, low selfesteem, depression, anxiety, grief, guilt and suicidal ideation [5]. In fact, research shows that women with infertility are prone to intimate partner violence, further aggravating the challenges faced by infertile women [10]. Majority of couples faced with the challenge of infertility battle with succession of life changes, helplessness, powerlessness, frustration, social segregation. They are also faced with challenge of life changes, including lifestyle, psychological and physical life changes. Most have to develop coping mechanism for social segregation linked with infertility including inapt responses of others [11]. Majority of individuals seek medical assistance as a treatment for infertility, with allopathy (treatment with drugs having opposite effects to symptoms) being the foremost treatments couples seek, Some couples pursue religious practice alongside with the treatment, while some others visited traditional healers $[12,13,14]$.

Infertility is a socially unacceptable condition, leading most infertile couples on a relentless "quest" for conception [15] and in some countries the social stigma of childlessness still leads to isolation and abandonment [15], there is hardly any research conducted to examine the experiences and health seeking behavior of infertile couples in Ekiti, considering the fact that infertility deeply affects the life of individuals, further studies should be conducted to explore the lived experiences of people with the ailment, and also provide advanced infertility treatment options.

\section{Methods}

This study used qualitative research design. The target population consisted of couples who were not able to conceive following the period of 12 months or more of trying to achieve pregnancy who were receiving treatment at Federal Teaching Hospital Ido-Ekiti, Ekiti state, Nigeria, from January to April 2019. Purposive sampling was used since in qualitative studies, a proper sample includes all participants with best information on the intended phenomenon based on lived experiences and interested in talking about their ideas regarding that phenomenon. The sampling criteria for the selection of participants were as follows:

1. couples that have failed to conceive within the period of 12 months and who has been diagnosed with either primary or secondary infertility and were currently receiving treatment at the health facility at the time the research study was conducted or more of trying to achieve pregnancy attending Federal Teaching Hospital IdoEkiti, Ekiti state.

2. Those willing to participate as at the time of the study.

Respondents were interviewed during clinic visits, where the researcher explained the study and obtained their informed consent before oral interview. Participants were informed that the research was voluntary and that they were free to terminate the interview at any time during the research process. Face-to-face, semi-structured interviews were used to collect data from the participants. Data collections focused on themes about the experiences and health seeking of couples towards infertility. The questions were aimed at exploring the experiences and health seeking behaviors of couples attending fertility clinic, in Federal Teaching Hospital, Ido-Ekiti, Ekiti state toward infertility. Open-ended questions were designed to ensure flexibility in line with the focus of the study. 
This method was utilized to create a conversation between the researcher and the respondents in order to explore the phenomena in detail. Each interview lasted between 30-40 minutes. The interviews were voice recorded with the participant's permissions and were transcribed verbatim except where translations were imperative. Interviews were conducted in English language. Interviews were transcribed, carefully read and double checked by the researcher for accuracy.

The data analysis was in two parts: qualitative data analysis and quantitative data analysis. Themes were identified and data were analyzed. Content analysis using open coding according to Tesch's approach was used to analyze the qualitative data. The narrative data gathered in terms of each theme was analyzed using open coding which involved breaking down, examining, comparing, conceptualizing and categorizing data and not merely describing themes. The data were manually content analyzed. The quantitative data were analyzed using statistical package for social sciences (SPPSS) version 20.The theoretical framework of this study was based on Roy's Adaptation model. This framework was already in past research about infertility.

\section{Ethics approval and consent to participate}

Before commencement of study, Ethical approval was obtained from the Ethics and Research Committee of Federal Teaching Hospital, Ido-Ekiti (Protocol number: ERC/11/26/158B). The purpose, aims and benefits of this study were explained to participants, permission to audio-record the interview and to take notes were obtained from the participants. Informed consent (verbal consent) was obtained from participants before data collection began. Verbal informed consent was taken from participant because of the sensitivity of the phenomenon being explored. Participants felt secured with verbal informed consent and this does not negate the ethics approval conduct for the study (see Supplementary F3). Participants were informed that all information to be from them would be kept confidential and used for research purposes only. They were also informed that anonymity would be maintained and that they have every right to withdraw their participation even after signing the consent without penalty or prejudicial treatment. Participants were ensured that results from this study would not harm them in any way (physical, psychological, emotional, social, legal or economic)

\section{Results}

\section{Quantitative Data}

Majority (80\%) of the participants were between ages 20-35 years. All the participants were Christians. Data collected on the ethnicity of the participants revealed that majority $(80 \%)$ were Yoruba. Ninety three percent of the participants were married. Data collected on years of marriage showed that a good number (33.3\%) of the participants had been married for 6-10 year and (8 of 15) has been married for $1-5$ years. Majority $(66.7 \%)$ of the participants had never had children i.e. primary infertility. Almost all the participants were female (13 of 15). (Tables 1 \& 2) 
Table 1

Socio-Demographic Profile of Participants

\begin{tabular}{|cllllllll|}
\hline ID & $\begin{array}{l}\text { AGE } \\
\text { RANGE }\end{array}$ & SEX & $\begin{array}{l}\text { MARITAL } \\
\text { STATUS }\end{array}$ & RELIGION & $\begin{array}{l}\text { ETHNIC } \\
\text { GROUP }\end{array}$ & $\begin{array}{l}\text { YEARS OF } \\
\text { MARRIAGE }\end{array}$ & PARITY & EMPLOYMENT \\
\hline 1 & $27-35$ & FEMALE & MARRIED & CHRISTIAN & UROBO & 2 & NONE & EMPLOYED \\
\hline 2 & $27-35$ & FEMALE & MARRIED & CHRISTIAN & YORUBA & 8 & NONE & UNEMPLOYED \\
\hline 3 & $36-48$ & MALE & MARRIED & CHRISTIAN & UROBO & 2 & NONE & EMPLOYED \\
\hline 4 & $36-48$ & FEMALE & MARRIED & CHRISTIAN & YORUBA & 5 & NONE & EMPLOYED \\
\hline 5 & $36-48$ & FEMALE & MARRIED & CHRISTIAN & YORUBA & 8 & 1 & EMPLOYED \\
\hline 6 & $27-35$ & FEMALE & SEPARATED & CHRISTIAN & YORUBA & - & 1 & EMPLOYED \\
\hline 7 & $27-35$ & FEMALE & MARRIED & CHRISTIAN & YORUBA & 7 & 1 & UNEMPLOYED \\
\hline 8 & $27-35$ & FEMALE & MARRIED & CHRISTIAN & YORUBA & 2 & NONE & EMPLOYED \\
\hline 9 & $27-35$ & FEMALE & MARRIED & CHRISTIAN & YORUBA & 6 & NONE & EMPLOYED \\
\hline 10 & $36-48$ & FEMALE & MARRIED & CHRISTIAN & YORUBA & 10 & 1 & EMPLOYED \\
\hline 11 & $36-48$ & FEMALE & MARRIED & CHRISTIAN & YORUBA & 2 & NONE & EMPLOYED \\
\hline 12 & $36-48$ & FEMALE & MARRIED & CHRISTIAN & IGBO & 4 & NONE & UNEMPLOYED \\
\hline 13 & $27-35$ & FEMALE & MARRIED & CHRISTIAN & YORUBA & 1 & NONE & SELF \\
\hline 14 & $36-48$ & MALE & MARRIED & MUSLIM & YORUBA & 2 & NONE & SELF \\
\hline 15 & $36-48$ & FEMALE & MARRIED & CHRISTIAN & YORUBA & 12 & 1 & EMPLOYED \\
\hline
\end{tabular}


Table 2

Summary of Socio-Demographic Profile of Participants

\begin{tabular}{|c|c|c|c|}
\hline \multicolumn{2}{|c|}{ SOCIO-DEMOGRAPHIC DATA } & \multirow{2}{*}{$\begin{array}{l}\text { FREQUENCY } \\
(n=15) \\
12\end{array}$} & \multirow{2}{*}{$\begin{array}{l}\text { PERCENTAGES } \\
\text { (\%) } \\
80.0\end{array}$} \\
\hline Age in years & $27-35$ & & \\
\hline & 36 and above & 3 & 20.0 \\
\hline \multirow[t]{3}{*}{ Religion } & Christianity & 15 & 100.0 \\
\hline & Islam & - & - \\
\hline & Others & - & - \\
\hline \multirow[t]{4}{*}{ Ethnicity } & Yoruba & 12 & 80.0 \\
\hline & Hausa & - & - \\
\hline & Igbo & 1 & 6.7 \\
\hline & Others & 2 & $13 . \% 3$ \\
\hline \multirow[t]{4}{*}{ Marital Status } & Married & 14 & 93.3 \\
\hline & Separated & 1 & 6.7 \\
\hline & Divorced & - & - \\
\hline & Widow & - & - \\
\hline \multirow[t]{2}{*}{ Employment Status } & Employed & 13 & 86.7 \\
\hline & Unemployed & 2 & 13.3 \\
\hline \multirow[t]{3}{*}{ Years of Marriage } & $1-5$ & 8 & 53.3 \\
\hline & $6-10$ & 5 & 33.3 \\
\hline & 11 and above & 1 & 6.7 \\
\hline \multirow[t]{3}{*}{ Number of Children } & Nil & 10 & 66.7 \\
\hline & $1-2$ & 5 & 33.3 \\
\hline & 3 and above & - & - \\
\hline \multirow[t]{2}{*}{ Sex } & MALE & 2 & 13.3 \\
\hline & FEMALE & 13 & 86.7 \\
\hline
\end{tabular}

Theme 1: Experiences of couple faced with the problem of infertility

\section{a) Experience of expectant mothers regarding infertility}

When participants were asked about their experiences as regards infertility, all (15 of 15) of the participants said that they had bad experiences and went through a lot of pain. Some of their responses were: 
'My experience? It's very bad, my experience is very bad because I have gone through series of tests, I have gone to theatre, done everything they asked me to do, nothing happened, I'm still here. (Female; married; secondary infertility)

Another respondent stated:

Nothing much, it's that I'm a bit curious, I want to know what exactly is happening, so as to know what steps to take as at when due so I don't want the delay to linger so that's my concern that's why I'm here. Of course, psychologically, when I see my mates or people that I'm older than or that we got married at the same time and they are carrying their babies, I will cry to my God, that I'm reminding him to do my own too.". (Female; married; primary infertility).

Another respondent answered "It was a bad experience o. like everything is frustrating self" (Male; married; primary infertility).

Another participant narrated:

Ah it's a, it's a bad experience, let me just put it that one because the joy of a woman when you are in your husband's house let everybody come and say congratulations and when, it's not really coming forth, it bothers the women more than the men, though in some homes the men are more concerned because what they want is their kids, they want their kids and all that, but the women what bothers them most time is if the person is unable to conceive for the main time, the husband might impregnant another person outside, the they, the, they might even ask her to leave the house and maybe she is the type that maybe the house they have is both of them that built it together, the same account and all that that she might almost kill herself". (Female; separated; secondary infertility)

\section{b) How the experiences have affected their wellbeing}

When participants were asked how the experiences had affected them, almost all (14 of 15) of the respondents explained they were affected in different spheres of life. Some of their responses were;

Very well, both spiritually, emotionally and even eh, in the family, you know when you are expecting something and it's not coming forth, there will be hearsay, here and there so that's it" "It affected much most of things I used to do I will see myself withdrawing back because people will be mocking and be walking about, they will be looking at you, they will be saying it's like your stomach is getting bigger, the next time they will say ah ah it's not pregnant. So it really affected me" (Female; married; primary infertility).

Another respondent narrated:

my wellbeing? Mmmm I can say its God because its affecting my wellbeing o, you know that the reason why the issue of childlessness is terrible one, you know there is nobody you can see that have no one issue or the other but when someone has an issue, the problem is covered. Do you understand? Because it may be the one that is happening under another person maybe more terrible than that you are going through but because lya alagbaja, the problem is covered, everything will now be maintaining in the inner part of their life. Do you understand? But as for me now, if I go out, except those, those places that they don't know me at all, maybe I am just going there for something and leave, but in my own environment, in my place of work before my husband asked me to withdraw, you know this issue, that's why, the issue that I am looking for the fruit of womb that is why it's always affecting our wellbeing like talking, people maybe talking concerning that your problem, they are stylishly making jest of you, you know, hearing that you know you must be depressed. If I wear clothe, if you dress, if you just feel like, okay now I 
am coming from another town to this place now, will I just wear rag? But if someone, if anyone sees me like this now, they will say, I don't know what is making her happy, they will remember the date you did wedding, they remember, since when you have been in your husband's house, so all those things, they may not mention your name but will indirectly be talking to you making you sad. It always affects wellbeing my sister I can't deceive you" (female; married; primary infertility).

Another participant answered:

“No, it has not affected my wellbeing” (female; married; primary infertility).

\section{c) Effects of infertility on social interactions and discussions with people}

When participants were asked whether they feel free discussing the issue (infertility) with people, majority (12 of $15)$ of the participants agreed they feel free discussing the problem with people they trust, few of the participants (2 of 15) discussed with Doctors; and One (1 of 15) feels she cannot confide in any one.

Some of their responses were;

There is no problem, they say ah ah problem shared is half solved, there is no problem I share it because when you share your problems, many people bring ideas, so when they bring ideas, like me I first embark on this herb of a thing, it didn't work out so I almost died in the process, it when I did, it's even a friend of mine, I was in a hospital, I have been treating myself in there,l, I want to do the operation there, it was now a friend that did his wife's own here that Dr. A is just the perfect man, he is this, he is that, in fact, that if I come here, I will be glad, very very happy to even do it that I won't feel the pain and I will even be happy I'm bringing money out, that was why I came here" (female; single; secondary infertility)

Another respondent answered:

It's only my husband, myself and Doctors. Tell friends the problem? Can they solve the problem? Can they solve it? Even the Doctors, they have the limit of can can do, so why should I discuss it? It is only if I see the same people passing through the same experience with me, I call the person and encourage the person that there is nothing impossible with God" (female; married; secondary infertility).

\section{d) Effects of infertility on the marriage}

When participants were asked whether the problem has affected their marriage, majority (13 of 15) of the participants stated the infertility problem has not affected their marriage. Few of the participants (2 of 15) however said it has affected their marriage. Some of their responses were;

I give God glory, it has not for once if I may not tell lies you know, men are different, you know I told you I have been on this thing for eight years, there are some people, there are some men that can never, except for six months they will be going here and there, she has not, she has not conceived let me find another alternative but so as for me o to God be the glory that for eight years it has not for once affected my marriage" (female; married; primary infertility).

"it hasn't in any way" (female; married; secondary infertility).

Another participant stated: "I told you he left me, he left me and I'm still alone" (female; single; secondary infertility). Another participant narrated: 
No, not at all, not at all but he had a girlfriend outside, he has a woman outside because to him I didn't want to give him a child. I'm the one delaying myself that I don't want to give him a child" (female; married; secondary infertility).

\section{e) Effect of infertility on job and family issues especially in-laws and friends}

When participants were asked whether the infertility issue has affected the job and family especially in-laws and friends, majority (13 of 15) were of the opinion that the infertility issue has never affected their jobs and families especially in-laws and friends. Few stated it has affected their relationship with people. Some of their responses were;

No. I'm so free to the family, to my in-laws, even to those who are mocking, I will just tell them don't worry my God is there, He will do it. He was the one that gave us this girl He will do it again. The only thing if there is anything I am supposed to do for them I will do it'. (Female; married; primary infertility).

Another respondent answered: "It doesn't affect it much not in any way, my relationship with in-laws is good" (Female; married; primary infertility).

Another respondent stated:

Yes. I'm no more working now, my husband asked me to stop working because the work I used to work I used to bend so they said bending can also affect it. I have good relationship with my in-laws" (Female; married; primary infertility).

Another participant narrated:

Yes yes, hmm, you know by seeing people, okay now I have been married for eight years now without nothing, those that are married after me, maybe 2 or 3 years. Before I was working in a school, in a private school, maybe just, some people will be saying eh, maybe you correct the child .Do you understand? But when she won't have a child? Why won't she beat my child? Do you understand? Why won't she beat my kini kor girl, when she doesn't have a child of her own. Do you understand? They will just be looking for your mistake, so as to be able to use it to mock you Ah. Do you understand it?" Participant broke into tears and I had to reassure and console her (Female; married; primary infertility).

\section{f) Opinion on the role of the man's family so far}

When participants were asked about the role of the man's family so far, majority (12 of 15) of the participants were of the opinion that the families have played positive roles so far and have proved supportive. Some of their responses were; "Some have given me "agbo" and some have taken me to their church for their pastor to pray for me" (female; married; primary infertility).

Another participant stated "They are trying their best through spiritual ah, through prayers they are trying their best they could do" (female; married; primary infertility). Another respondent answered: "They are very nice, they are trying their best" (female; married; primary infertility).

\section{g) Experience of enough support from the husband}

When participants were asked whether they were getting enough support from the husband, majority (14 of 15) of the participants claimed their husbands were supportive. Some of their responses were; "Yes, he gives me enough support, we came together" (female; married; primary infertility). 
Another respondent stated: "Yes. A very loving man" (female; married; secondary infertility).

Another participant narrated:

He had a girlfriend outside; he has a woman outside because to him I didn't want to give him a child. I'm the one delaying myself that I don't want to give him a child" (female; married; secondary infertility).

\section{h) Relationship between infertility and distrust in the marriage}

When participants were asked whether the infertility issue had caused distrust in the marriage, almost all (14 of 15) were of the opinion that the infertility issue had never caused any distrust in their marriage. Some of their responses were; "No it hasn't. He understands me” (female; married; primary infertility).

Another respondent stated: "Never, never" (female; married; primary infertility).

\section{Health seeking behaviors of couples towards infertility}

\section{a) Opinion on measures taken to solve the problem so far}

When participants were asked the measures taken to solve the problem so far, all (15 of 15) of the participants stated they had visited many places for treatment including hospitals and churches. Some of their responses were;

I have been to many hospitals and also prayer so it is more eh. One of my friend's husband that said we should come and see a specialist so we would know what to do" (female; married; primary infertility).

Another respondent answered: "I have done series of tests. Shebi I told you series of tests, I have taken drugs, test and tests" (Female; married; secondary infertility)

Another participant answered: "I have had surgery on my tummy last year, then I have done series of tests for review today" (Female; married; primary infertility).

\section{b) Opinion on what compelled participants to taking such action}

When participants were asked what compelled them to taking such action, all (15 of 15) of the participants revealed that they took those steps in order to solve the existing problems and have kids of their own. Some of their responses were;

A year and after, we did not see anything, I have been eh, I have done scan, I have done many things, so when one is looking for something, you have to seek for medical advice is child health something" (Female; married; primary infertility).

Another respondent answered: "Ah as you know when someone is expecting something and it's not coming forth so you give everything trials. So that's all"(Female; married; primary infertility)

Another respondent stated: "Because I want to have kids and I don't want to lose my man" (Female; single; secondary infertility).

\section{c) Opinion on where the participants went first upon noticing the problem}

When participants were asked where they went first upon noticing the problem, all (15 of 15) of the participants revealed they visited the hospital first. Some of their responses were; 
A respondent answered: "It's hospital" (female; married; primary infertility)

Another respondent answered: "Ikorodu General Hospital" (female; married; primary infertility). Another respondent answered: "Hospital" (Female; married; primary infertility).

\section{Opinion on the expectations of the participants during their first visit to the fertility clinic}

When participants were asked their expectations during their first visit to the fertility clinic, all (10 of 10) of the respondents revealed they were optimistic to get pregnant after their visit to the hospitals. Some of their responses were; "I expected that after treatment I will just take in, but after treatment I did not see anything" (female; married; primary infertility). Another respondent answered: “Conception" (female; married, primary infertility). Another respondent answered: "To get pregnant" (Female; married; secondary infertility).

\section{e) Opinion on where the participants are receiving help/treatment apart from the fertility clinic}

When asked on where the participants are receiving help/treatment apart from the fertility clinic, majority (14 of 15) of the respondents claimed they are not receiving any treatment from any other place apart from the fertility health clinic. Some of their responses were; "No. Private hospital didn't work so I came here" (Female; married; primary infertility). Another participant answered: “At all. No" (Female; married; primary infertility)

\section{f) Opinion on whether the participants are on medications, IVF or other treatment options}

When the participants were asked whether they are on medications, IVF or other treatment options, majority (12 of 15 ) of the participants agreed they were on medications. Some of their responses were;

I did ultrasound and they placed me on medications but I don't know the names. Some doctors eh, they withdraw the drugs but my mind is telling me is those hormonals eh injection, maybe progesterone and this folic acid and chromids. That is the drugs that can boost my hormone" (female; married; primary infertility).

Another participant stated: "I'm on chromid" (Female; married; secondary infertility)

\section{g) Opinion on whether participants combine treatments with other form of treatment from other sources and which treatment and why}

When asked on whether participants combine treatments with other form of treatment from other sources and which treatment and why, all (15 of 15) the respondents revealed they do not combine treatments in the hospital with other treatments. Some of the responses were;

A participant answered: “No. Not at all” (Female; married; secondary infertility)

\section{h) Opinion on whether the treatment options are working}

When participants were asked whether the treatment options are working, majority (12 of 15) of the respondents were of the opinion that the treatment options were not working. Some of their responses are;

"No. No because the reason why I said no is that eh, you know when you are doing something, when you are taking something, when you are taking one treatment and its not getting you your desire it means its not working" (female; married; primary infertility)

Another participant answered: "No. I have not seen any results so the answer is no" (Female; married; secondary infertility). 


\section{i) Opinion on the challenges the participants are facing during the treatment process}

When asked the challenges the participants are facing during the treatment process, a good number (8 of 15) of the participants were of the opinion that they faced some challenges. Some of their responses were; "I still feel pain in my lower abdomen due to the surgery. I think eh healing is taking place" (Female; married; primary infertility).

Another participant answered: "It's only at times when we come here, we wait, wait and wait" (Female; married; secondary infertility).

Another participant stated: "Ah, Stress and pain but I just pray it works cos they say all things work out for good" (Female; separated; primary infertility).

\section{j) Opinion on possible complications participants are facing in relation to present treatment}

When asked on the possible complications participants are facing in relation to present treatment, majority (12 of 15) of the participants claimed they do not have any complications towards the present treatment. Some of their responses were;

"Complications? Through the treatment? No" (Female; married; primary infertility). Another participant answered: "At all, no complain" (Female; married; primary infertility).

\section{k) Opinion on whether the treatment options are socially and emotionally acceptable}

When asked whether the treatment options are socially and emotionally acceptable, majority (13 of 15) of the participants revealed that taking the drugs was never a problem for them. Some of their responses were; "Yes. It's okay so far l'm fine healthwise" (Female; married; primary infertility).

Another participant stated: "I do not have a choice they are the ones that knows the best, I'm not a doctor so I just followed what they asked me to do, it's okay" (Female; separated; secondary infertility).

Another respondent answered: "Yes, it's okay taking drugs once in a day, it's not a big deal" (Female; married; primary infertility).

\section{I) Opinion on whether family members would be financially able to take care of the treatment option}

When asked whether family members would be financially able to take care of the treatment option, majority (14 of 15) of the participants claimed their family members can provide the financial assistance needed for the treatment options. Some of the responses were; "Yes. I can" (Male; married; primary infertility).

Another participant answered: "That I can have it in the financial aspect? Yes, yes" (female; married; primary infertility).

Another participant answered:

"Of course they will" (Female; married; secondary infertility).

\section{m) Opinion on how infertility will best be handled}

When asked how infertility will best be handled, all (15 of 15$)$ the respondents suggested going to the hospital as early as possible prior to notice or observed delay. Some of their responses were; 'Take treatment and just leave everything in God's hands" (Female; married; primary infertility). Another participant stated: "hmm. I think the best thing, best way to handle such a case is to come to hospital for solution" (Female; married; primary infertility). 
Another participant narrated:

Early detection, if you notice anything in your body, go to the hospital is the first thing rather than running helter skelter, going to the hospital to detect the exact cause then treat accordingly, not leaving aside anything about it ,I believe there is nothing God cannot do, even as the doctors are treating, they cannot do, even as the doctors are treating, they are not God, it's only God that heals, they only care and believe they curb infertility. early detection and going to the right place at the right time for proper treatment because I noticed that as old but the individual involved either man or woman gets older, the more difficult for it to be treated, so go to the hospital early is the way" (Female; married; primary infertility).

\section{Discussion Of Findings}

The findings of this study provided insights into the experiences and health seeking behaviors of women with infertility. In this study, most of the participants were within the age range of 20-35years, married and belonged to the Christian religion. These results are similar to that gotten from a study where higher proportion of the women were within the age of 25-29 years [16].

Majority of the participants had a tertiary education, this may have an effect on their health seeking behavior, as majority of them chose to go to the hospital for treatment. Similar results were obtained in studies [16], [17]. Majority of the participants had primary infertility as they had been married for 6-10 years and had no child. This goes to say that the incidence of primary infertility higher than secondary infertility [7].

Data gathered on experiences revealed that when all the participants described their experiences as bad and unpalatable. Furthermore almost all the participants claimed that their present condition (infertility) has affected them in all spheres of life. One of the participants even said she had to withdraw from her place of work due to shame verbal abuse by colleagues. The findings of this study is however consistent with the findings of Philip \& Philip, 2014 [18], a study conducted among the Ghanaian population where couples faced with infertility problems similarly expressed unhappiness towards their entire life. This is also in line with the assertions of Fledderjohan, 2012 [19], who viewed infertility as contributing to high level of psychological distress particularly in the developing countries [19] as against the experiences of women in developed countries where the concept of "voluntary childbearing" is common. The concept of voluntary childbearing is however not the case in the African culture where having children are key to a woman's achieving adult status and gaining acceptance in the community [20]. This is further corroborated by the findings of Sundby \& Jacobus (2011) [21], where giving birth to a child (childbearing) gives a woman the right to share in her husband's property and wealth [21].

Data collected on the effect of infertility on family relationship revealed that majority (13 of 15) of the participants claimed that it has never affected their relationship with their husband and families including their in-laws, although two of the participants said it has affected their marriage as it has led to infidelity in marriage (extramarital affair by husbands). This is however contrary to the findings of a qualitative study conducted in Ghana "on the family impact of infertility," where most of the participants reported that infertility had destroyed their marriages and also affected them in many wise [18].

Regarding social support systems, majority of the participants claimed that their families including their in-laws have been supportive by the way of "prayers, fasting and use of encouraging words". These findings were not consistent with the findings of a study conducted by Inhorn, 2013 [22], where more than half (58.8\%) the participants claimed that their family members were not supportive and that their in-laws said they were 
responsible for their childlessness [22]. Similarly, in a study conducted in Pakistan, pressure from husbands and inlaws compelled the infertile women to seek care [23].

Psycho social effects of infertility recorded in this study ranged from anxiety, sadness, withdrawal and low selfesteem. It will be beneficial if health providers give counseling to address the emotional and psychological effects of infertility, this is to ensure that such symptoms are identified and managed early. Similar symptoms were also noted in participant in studies $[15,24,25]$.

The study revealed that participants used a combination of orthodox medicine and Spiritual remedies to treat infertility. Participants used these strategies concurrently; combining hospital visits with prayers and fasting. This pattern may be seen because several women with infertility perceive that some spiritual forces might be responsible for their ailment, which God can cure. This finding is consistent with previous studies where majority of the participants had visited physicians but also visit churches for treatment. In contrast to the findings of this study, medical treatment was the only choice of treatment for participants in some studies $[25,26]$.

\section{Conclusion}

In conclusion, findings from this research indicated that the experiences of the participants were similar as almost all of them described their experiences as unpalatable and painful, as they expressed unhappiness and concern about their present state. Moreover the entire participant had a good health seeking behavior.

\section{Recommendation}

Psychological support in form of counseling is necessary in couples with infertility to avoid mental health ailments like depression and anxiety disorders. Social supports group should be created where people with similar challenges can come together.

Further studies should be conducted to understand the lived experiences of couples with infertility.

\section{Abbreviations}

IVF: In vitro Fertilization

\section{Declarations}

Acknowledgement: The researchers want to appreciate all participants who participated in the study.

Author Contribution Statement: Author DTE and KQN designed the study, performed the analysis, and wrote the first draft of the manuscript. Authors DTE, KQN, AO, OOO and Author FM managed the analyses of the study. Author $\mathrm{OOO}$ and FM managed the literature searches. DTE and AO revised the manuscript. All authors read and approved the final manuscript.

Ethics approval and consent to participate: Ethical clearance was obtained from Ethics and Research Committee of Federal Teaching Hospital, Ido-Ekiti, Ekiti State, Nigeria. (Protocol number: ERC/2018/11/26/158B)

Consent for publication: Not applicable

Page $14 / 16$ 
Availability of data and material: The datasets generated/analysed during the current study are available from the corresponding on reasonable request

Competing Interests: The authors at this moment declare that they have no competing interests associated with this study.

Funding: This research did not receive any specific grant from funding agencies in the public, commercial, or notfor-profit sectors

\section{References}

1. Zegers-Hochschild F, Adamson GD, de Mouzon J, Ishihara O, Mansour R, Nygren K, Sullivan E, Van der Poel S. The international committee for monitoring assisted reproductive technology (ICMART) and the world health organization (WHO) revised glossary on ART terminology, 2009. Human reproduction. 2009 Oct 4;24(11):26837.

2. Tabong PT, Adongo PB. Understanding the social meaning of infertility and childbearing: a qualitative study of the perception of childbearing and childlessness in Northern Ghana. PloS one. 2013 Jan 16;8(1): e54429.

3. Nwobodo El, Isah YA. Knowledge, attitude and practice of child adoption among infertile female patients in Sokoto north-west Nigeria. The Nigerian postgraduate medical journal. 2011 Dec;18(4):272-5.

4. Dattijo LM, Andreadis N, Aminu BM, Umar NI, Black KI. The prevalence and clinical pattern of infertility in Bauchi, northern Nigeria. Tropical Journal of Obstetrics and Gynaecology. 2016;33(1):76-85.

5. Omoaregba JO, James BO, Lawani AO, Morakinyo O. Psychosocial characteristics of female infertility in a tertiary health institution in Nigeria. Annals of African Medicine. 2011;10(1).

6. Panti AA, Sununu YT. The profile of infertility in a teaching Hospital in North West Nigeria. Sahel Medical Journal. 2014 Jan 1;17(1):7.

7. World Health Organization. (2004). Challenges in reproductive health research. Geneva: World Health Organization.

8. Mohammad K, Ardalan A. An overview of the epidemiology of primary infertility in Iran. Journal of reproduction \& infertility. 2009 Oct;10(3):213.

9. Diamond RM. Infertility and Pregnancy Loss in Couple and Family Therapy. Encyclopedia of Couple and Family Therapy. 2017:1-5.

10. Aduloju PO, Olagbuji NB, Olofinbiyi AB, Awoleke JO. Prevalence and predictors of intimate partner violence among women attending infertility clinic in south-western Nigeria. European Journal of Obstetrics \& Gynecology and Reproductive Biology. 2015 May 1; 188:66-9.

11. Loke AY, Yu PL, Hayter M. Experiences of sub-fertility among Chinese couples in Hong Kong: A qualitative study. Journal of Clinical Nursing. 2012 Feb;21(3-4):504-12.

12. Gannon K, Glover L, Abel P. Masculinity, infertility, stigma and media reports. Social Science \& Medicine. 2004 Sep 1;59(6):1169-75.

13. Fatima P, Hossain MM, Rahman D, Hossain HB, Hossain HN, Hossain FA. Treatment Seeking Behavior and the Profile of Infertile Patients Attending the Tertiary Infertility Center at Dhaka. Journal of Bangladesh College of Physicians and Surgeons. 2016;34(3):140-4. 
14. Meskelu J, Berhane Y. Experiences of women with infertility and their treatment seeking practices: a qualitative study. Ethiopian Journal of Reproductive Health. 2018 Dec 7;10(4).

15. Fehintola AO, Fehintola FO, Ogunlaja OA, Awotunde TO, Ogunlaja IP, Onwudiegwu U. Social meaning and consequences of infertility in Ogbomoso, Nigeria. Sudan Journal of Medical Sciences. 2017;12(2):63-77.

16. Sami N, Ali TS. Health seeking behavior of couples with secondary infertility. Journal of College of Physicians and Surgeons Pakistan. 2006;16(4):261.

17. Omosun AO, Kofoworola O. Knowledge, attitude and practice towards child adoption amongst women attending infertility clinics in Lagos State, Nigeria. African Journal of Primary Health Care \& Family Medicine. $2011 ; 3(1)$.

18. Philip T, Philip B. Infertility and childlessness: a qualitative study of the experiences of infertile couples in Northern Ghana. BMC Pregnancy and Childbirth. 2014;13(72), 1-10.

19. Fledderjohhann JJ. 'Zero is not good for me': implications of infertility in Ghana. Human Reproduction. 2013; 27(5): 1383-1390.

20. Magadi M, Agwanda A. Investigating the association between HIV/AIDS and recent fertility patterns in Kenya. Social Science \& Medicine. 2014; 71(2): 335-344.

21. Sundby J, Jacobus A. Health and traditional care for infertility in The Gambia and Zimbabwe. In: Boerma, JT.; Mgalla, Z., editors. Women and Infertility in sub-Saharan Africa: A Multidisciplinary Perspective. Amsterdam: Royal Tropical Institute. 2011.

22. Inhorn M. The worms are weak': male infertility and patriarchal paradoxes in Egypt. Men and Masculinities. 2013; 5(3): 236-256.

23. Neefolar S, Tazeen S. Health seeking behavior of couples with secondary infertility. Journal of the College of Physicians and Surgeons--Pakistan: 2016; 16(4): 261-264.

24. Zandi M, Mohammadi E, Vanaki Z, Shiva M, Bagheri Lankarani N, Zarei F. Confronting infertility in Iranian clients: a grounded theory. Human Fertility. 2017 Oct 2;20(4):236-47.

25. Tahiri FB, Kalaja D, Bimbashi EK. The Lived Experience of Female Infertility The Case Of Muslim Rural Women Leaving In Albania. European Scientific Journal. 2015 Apr 1;11(11).

26. Bennett LR, Wiweko B, Bell L, Shafira N, Pangestu M, Adayana IP, Hinting A, Armstrong G. Reproductive knowledge and patient education needs among Indonesian women infertility patients attending three fertility clinics. Patient education and counseling. 2015 Mar 1;98(3):364-9

\section{Supplementary Files}

This is a list of supplementary files associated with this preprint. Click to download.

- INTERVIEWGUIDESupplemmentaryF1.docx

- COREQchecklistsupplementaryF2.docx 